\section{Eficácia social da prestação jurisdicional}

Teori Albino Zavascki

Juiz, do TRF - 4 Região $^{-}$

Professor de Processo Civil na UFRGS

Il est contradictoire que le peuple soit à la fois misérable et souverain

Tocqueville $^{1}$

\section{Abstract}

Law's norms have by their owen nature, a calling to transform society. Seen in this light, Law will only achieve its actual realization when working out transformations at reality level, by making it draw nearer to the normative ideal. Therefore, it will be the task os the legal force and specially of the Judiciary Power - thar is its worker par excellence-to interpret and to apply it in a way that, in the bighest degree, offers the social results ideally anticipated by the legislador.

With this, and only so, will Law be recogn zed as a genuine tool for regulating State and society.

\section{Introdução}

Eficácia jurídica e eficácia social do direito

1. Em direito, o termo "eficácia" não é unívoco, podendo ser compreendido basicamente em dois sentidos. Vista como fenômeno puramente normativo, eficácia é a aptidão da norma jurídica para gerar efeitos no mundo jurídico. "A eficácia da regra jurídica é a sua incidência" e esta "se passa no mundo dos pensamentos", ensina com o sentido indicado, Pontes de Miranda ${ }^{2}$. Assim, "eficácia jurídica é a que se produz no mundo do direito como decorrência dos fatos jurídicos e não ...a mudança que atua nas relações jurídicas", ensina o grande jurista ${ }^{3}$.

2. Mas há um segundo sentido de eficácia, em direito: o que designa a aptidão da norma jurídica para produzir efeitos na realidade social, ou seja, para produzir, concretamente, condutas sociais compatíveis com as determinações ou os valores consagrados no preceito normativo. Aqui a eficácia da norma de direito é fenômeno que se passa, não no plano puramente formal, mas no mundo dos fatos e por isso mesmo é denominada eficácia social ou efetividade. Uma norma pode, destarte, ser juridicamente eficaz, sem, no entanto, ser socialmente eficaz, como observou José Afonso da Sil $\mathrm{va}^{4}$. Enquanto a eficácia jurídica da norma representa, pela sua incidência, a jurisdicização de certo fato ou estado de fato, a eficácia social representa a concretização da vocação prospectiva e transformadora da norma do direito.

3. A eficácia social do direito foi e continua sendo tema de preocupação dos juris tas. Léon Duguit salientou que o efetivo respeito da regra é condição para que ela deixe de ser uma regra moral ou econômica e se transforme em regra jurídica ${ }^{5}$. Hans Kelsen, ele próprio, considerou que, em determinadas circunstâncias, a eficácia da norma - que "consiste em que esta em geral é cumprida e se não cumprida é aplicada", é condição da sua própria validade ${ }^{6}$. Entre nós, Miguel Reale, após definir eficácia como sendo a "aplicação ou execução da norma jurídica, ou, por outras palavras, é a regra jurídica enquanto conduta humana",

R. Fac. Direito UFRGS, Porto Alegre, 9(1): 248-253, nov. 1993 afirmou que "o Direito autêntico não é apenas declarado mas reconhecido, é vivido pela sociedade, como algo que se incorpora e se integra na sua maneira de conduzir-se. A regra de direito deve, por conseguinte, ser formalmente válida e socialmente eficaz"7. Essa perspectiva é que dá sentido ao direito como tendo "caráter de força social propulsora" que "visa proporcionar, por via principal aos indivíduos e por via de conseqüência à sociedade, o meio favorável ao aperfeiçoamento e ao progresso da humanidade ${ }^{u}$, segundo anotou Vicente Ráo ${ }^{8}$

4. Do exposto colhe-se, portanto, que a eficácia social da norma jurídica está vinculada a dois referenciais: o conteúdo normativo (o dever-ser) de um lado e, de outro, as condutas sociais (o ser). A norma será tanto mais eficaz quanto maior for a aproximação e a atração que o plano da normatividade puder exercer sobre o plano da realidade.

Brasil - 1993: ser e dever-ser

5. No campo do direito constitucional, a eficácia social das normas tem merecido atenção especialíssima dos juristas. "Constituição e realidade não podem restar isoladas uma da outra", observou Konrad Hesse?. Mais agudamente, Celso Antonio Bandeira de Mello observa que "A Constituição não é um simples ideário. Não é apenas uma expressão de anseios, de aspirações, de propósitos. É a transformação de um ideário, é a conversão de anseios e aspirações em regras impositivas. Em comandos. Em preceitos obrigatórios para todos: órgãos do Poder e cidadãos ... A seriedade do ato constituinte impediria a suposição de que os investidos em tão alta missão, dela se servissem como simples válvula de escape para emoções antecipadamente condenadas, por seus próprios emissores, a permanecerem no reino da fantasia"10

6. Com efeito, é no plano constitucional igualmente, que se pode verificar, com nitidez absoluta, os contrastes entre a realidade e a normatividade, entre o ser e o dever-ser entre a praxis e o valor, a comprovar a importância das preocupações em torno da eficácia social das normas. No caso brasileiro, alguns exercícios de comparação são favorecidos com a recente publicação do Anuário Estatístico do Brasil - 1992, da Fundação Instituto Brasileiro de Geografia e Estatística ${ }^{11}$. Assim, por exemplo, no plano da normatividade, a Constituição de 1988 erigiu entre os objetivos fundamentais da Nação erradicar a pobreza e a marginalização, reduzir desigualdades sociais e regionais, garantir o desenvolvimento nacional, promover o bem a todos, sem qualquer espécie de preconceito, enfim, construir uma sociedade livre, justa e solidária (art. $3^{\circ}$ ). Os dados estatísticos, a sua vez, demonstram, com crueza, o grande fosso que separa o ideário constitucional e a realidade nacional. Apenas como ilustração, atente-se para os seguintes dados colhidos do Anuário do IBGE: a renda per capita, na última década, apresentou um decréscimo de 5,6\%, e, pior ainda, acentuaram-se as desigualdades na sua distribuição, pois enquanto $10 \%$ das pessoas mais pobres detinham em 1990 apenas $0,8 \%$ da riqueza nacional, os $10 \%$ mais ricos acumulavam quase a sua metade $(48,7 \%)$. Dos cerca de sessenta e dois milhões de brasileiros que compõem a população economicamente ativa, $24 \%$ recebem, no máximo, um salário mínimo como remuneração e 52\% tem como remuneração máxima dois salários mínimos. Mais $8 \%$ deste universo (cerca de 5 milhões de pessoas), nada ou quase nada recebem, a não ser, quem sabe, alguns favores in natura para sua sobrevivência; apenas $3 \%$ ganham mais de 20 salários mínimos mensais; $53,7 \%$ da população mais jovem (entre 0 e 17 anos) integram famílias com renda de até meios salário mínimo per capita. As desigualdades regionais são alarmantes e podem ser resumidas nos dados sobre esperança de vida: a média brasileira de esperança de vida ao nascer é de 60,08 anos, mas na região sul é de 66,98 e no nordeste é de 51,57. Quem nasce no Rio Grande do Sul tem expectativa de viver 70,62 anos, mas se nascer na Paraíba este número cai para apenas 44,35 anos. A taxa de mortalidade infantil é, na média, 87,88 
por mil, mas na região sul é de 61,80 por mil e no nordeste 121,36 por mil. A taxa de analfabetismo, que na média brasileira é de $19,6 \%$ é de $11 \%$ na região sul e de $39,1 \%$ na rẹgião nordeste. E assim por diante. Vejase o que a realidade mostra no campo dos preconceitos de cor: a taxa de analfabetismo, como disse, é de 19,6\%. Entre os brancos, porém, a taxa é de $12 \%$ e entre os pretos de 30\%. Em termos de remuneração, os trabalhadores de cor preta ou parda recebem, em média, $41 \%$ e $48 \%$ menos que os de cor branca. No campo da educação (que, no plano normativo constitucional é "direito de todos e dever do Estado e da família", art. 205), os dados, como se viu, são preocupantes, com média de $19,6 \%$ de analfabetos entre pessoas com mais de sete anos de idade, o que significa uma legião de cerca de vinte milhões de pessoas. De cada mil alunos que entram na escola, apenas $22 \%$ concluem o primeiro grau. $31,7 \%$ dos adolescentes (que no plano normativo gozam de proteção especialíssima - art. 227 da CF), são obrigados a deixar a escola para ajudar no sustento familiar. Enfim, estes são alguns poucos exemplos colhidos das estatísticas oficiais a demonstrar o distanciamento existente entre o ideal normativo e a realidade social. Outros tantos poderiam ser anotados para demonstrar como os direitos constitucionais, especialmente os chamados direitos de segunda geração (direitos sociais) estão assegurados apenas no plano da normatividade, sem correspondência no plano real: direito a salário mínimo suficiente para sustentar a família; direito à moradia, à saúde, proteção à infância, à adolescência.

7. O quadro de dessintonia entre o dever-ser e o ser traz à baila, portanto, com inteira atualidade, o tema da eficácia social do direito. "Cumprida toda uma trajetória de avanços sociais", diz Paulo Bonavides, "das Constituições já não se reclamam direitos, mas garantias. Os direitos existem de sobra, com tamanha abundância na esfera programática que formalmente o texto constitucional resolveu com o voto do constituinte todos os problemas básicos de edu250 cação, saúde, trabalho, previdência, lazer e, de último, até mesmo a qualidade de vida, consagrando um capítulo à ecologia, ou, com mais propriedade, ao meio-ambiente $^{112}$. "Mas o verdadeiro problema do Direito Constitucional da nossa época", diz ele, "está, ao nosso ver, em como juridicizar o Estado Social, como estabelecer e inaugurar novas técnicas e institutos processuais para garantir os direitos sociais básicos, a fim de fazê-los efetivos"13. Está lançado, assim, o desafio aos juristas e, especialmente, aos juízes, e as observações abaixo terão por meta apontar alguns possíveis caminhos.

Poder Judiciário: Eficácia Social da Prestação Jurisdicional

8. Transformar o ideário constitucional em condutas e realidades concretas, não é, certamente, tarefa de alçada exclusiva do Poder Judiciário. Ao contrário, trata-se de empreendimento necessariamente compartilhado entre os Poderes do Estado e a própria sociedade, Urge, porém, que esta grande causa seja de uma vez encetada, com coragem e vontade política e o papel do Judiciário será, induvidosamente, da maior importância. É certo que a efetivação dos programas constitucionais dependerá fundamentalmente da iniciativa dos demais Poderes, aos quais compete a formulação de políticas públicas adequadas e a aprovação dos mecanismos institucionais e legais para a respectiva implementação. Mas o Judiciário não poderá se eximir da sua fatia de responsabilidade, que consiste, essencialmente, em prestar jurisdição mediante pronunciamentos que extraiam do sistema normativo soluções as mais adequadas possíveis à produção dos resultados previstos pelo Constituinte.

9. A questão que se coloca, portanto, é a de saber que caminhos poderá trilhar o Judiciário para que o exercício de sua missão constitucional resulte em aprimoramento do grau de eficácia social das normas. Esta preocupação implica, por si só, uma tomada de posição: a do abandono das orientações segundo as quais a interpretação e a aplicação do direito é simples operação mecânica, meramente silogística, cal- cada unicamente em fórmulas e formas positivamente estabelecidas. $\mathrm{Na}$ verdade, os tempos atuais já não comportam juízes de costas para a realidade, pena de dar razão aos que acham que os juristas "pelas suas tresnoitadas teorias, conceitos e formulações, sejam olhados, pela generalidade dos demais seres humanos, como espécimes de uma fauna em vias de extinção e, por isso mesmo, cada dia menos decisiva no curso da vida social, enquanto juristas"14. $\mathrm{O}$ caminho do positivismo, próprio do estado liberal - individualista, é obsoleto frente à atual configuração do Estado Social de Direito e quanto $a$ isso, parece, ninguém mais põe dúvida.

10. Por outro lado, ao Judiciário não se permite o caminho radicalmente oposto, de substituição de juízos de legalidade por juízos de conveniência, ou da substituição da ideologia constitucional por ideologias pessoais e, muito menos, da substituição da normas criadas pelo Estado Democrático de Direito por normas de sistemas ditos alternativos. Tal caminho, além de importar usurpação, pelo Judiciário, das funções dos outros Poderes (estes ungidos pelo voto popular), representaria a negação da sua única base de legitimidade, que é a Constituição, e transformaria seus atos em atos de puro arbítrio. Já se disse, com propriedade, que "o Estado de direito não pode renunciar, nem às leis bem pensadas, nem a uma magistratura que tome a sério a sua vinculação à lei e ao direito"15

11. Assim, a busca de decisões judiciais que levem à eficácia social do direito deve ser empreendida exaurindo-se os mecanismos oferecidos pelo próprio sistema jurídico do Estado de Direito Constitucional. Muitas trilhas aguardam ser exploradas, algumas abertas há mais tempo, outras desbravadas por doutrinas interpretativas mais modernas. German J. Bidart Campos, por exemplo, indica uma excelente relação com nada menos que quinze itens, "para interpretar constitucionalmente os direitos humanos", de modo a dar-lhes mais efetiva proteção ${ }^{16}$. De nossa parte, permitimo-nos indicar, entre os muitos caminhos aponta- dos pela doutrina, algumas sugestões de pautas de trabalho que, se exploradas com determinação, poderão certamente oferecer resultados satisfatórios.

12. No que se refere à interpretação da Constituição, além dos instrumentos tradicionais e clássicos, merecem indicação os seguintes veios, ainda não exaustivamente aproveitados pela jurisprudência:

a) reconhecimento do grau de eficácia jurídica e da normatividade dos princípios constitucionais, que devem funcionar "como critério de interpretação e de integração, pois são eles que dão a coerência geral ao sistema", e como "elementos de construção e qualificação" dos conceitos constitucionais básicos, exercendo ainda "uma função prospectiva, dinamizadora e transformadora, em virtude da força expansiva que possuem (e de que se acham desprovidos os conceitos, desde logo por causa de suas amarras verbais)"17;

b) exploração máxima da normatividade e da eficácia vinculante das normas programáticas, normas que, segundo vozes influentes do moderno constitucionalismo, teriam o condão de determinar até mesmo "a cessação de vigência, por inconstitucionalidade superveniente, das normas legais anteriores que disponham em sentido contrário", além de proibir "a emissão de normas legais contrárias" bem como "a prática de comportamentos que tenham a impedir a produção de atos por ela impostos - donde inconstitucionalidade material em caso de omissão"18;

c) reconhecimento da juridicidade e normatividade dos "direitos fundamentais de terceira geração", baseados no princípio da solidariedade social e da fraternidade e decorrentes da evolução expansiva dos direitos fundamentais. "Dotados de altíssimo teor de humanismo e universalidade", ensina Paulo Bonavides, "os direitos da terceira geração tendem a cristalizar-se neste fim de século enquanto direitos que não se destinam especificamente à proteção dos interesses de um indivíduo, de um grupo ou de um Estado. Têm primeiro por destinatário o gênero humano mesmo, num momento 
expressivo de sua afirmação como valor supremo em termos de existencialidade concreta $^{119}$. Dentre eles destacam-se o direito ao desenvolvimento, ao trabalho, à saúde, à alimentação, ao meio ambiente sadio e os direitos difusos de um modo geral ${ }^{20}$. É certo que a implementação de tais direitos favorecerá - porque dela será necessariamente dependente - a implementação dos direitos sociais básicos, denominados direitos de segunda geração;

d) outro importante instrumento de eficácia social do direito é a devida valorização dos deveres sociais, aliás previstos no art. 29 da Declaração Universal dos Direitos do Homem. "Fala-se muito mais dos direitos do que dos deveres humanos", diz, com acerto, Adolfo Gelsi Bidart. Entretanto "...uns e outros têm a mesma fonte e ponto de partida e ambos, entre si, se relacionam e se assistem para alcançar sua efetiva realização"21. Referimo-nos a deveres, não do Estado mas dos indivíduos, em prol dos demais integrantes da comunidade, e "sem que o sujeito obrigado ativa e universalmente personalize e concretize com cada um destes indivíduos um vínculo obrigacional particularizado"22. A valorização, pelo intérprete, dos deveres do indivíduo para com a comunidade pode oferecer resultados importantes no campo da hermenêutica. Além de conter ímpetos demagógicos, o aplicador do direito, ao examinar interesses particulares e individuais, será levado a estabelecer critérios de ponderação que melhor conciliem demandas individuais com os interesses do bem comum. É o caso, por exemplo, dos avanços que se operam nas Cortes Constitucionais da Europa relativamente interpretação do princípio da isonomia que, segundo refere Paulo Bonavides, é considerado como princípio que encerra em si uma igualdade concreta, niveladora, "operada na esfera fática propriamente dita e não em regiōes abstratas ou formais do Direito", sendo que "a igualdade material faz livres aqueles que a liberdade do Estado de Direito da burguesia fizera paradoxalmente súditos $^{\text {123. }}$.
13. No que se refere às normas infraconstitucionais, o que de mais prioritário se evidencia para que a interpretação leve a resultados eficazes, é, inquestionavelmente, o resguardado da unidade do ordenamento jurídico, unidade que, como se disse, deve se estabelecer a partir da Constituição. Imantado pela força ordenadora dos princípios e normas programáticas da Carta Magna, o intérprete será levado a vestir o direito ordinário com as cores constitucionais, e a interpretá-lo e aplicá-lo à luz dos valores constitucionais, da ideologia constitucional, do ideário constitucional. A partir daí, como se pode perceber, haverá uma gama expressiva de instrumentos hermenêuticos a serem explorados.

14. Para finalizar, é indispensável que se alerte para um ponto mais. Por maiores e melhores que sejam os recursos hermenêuticos disponiveis, eles, por si só, podem ser absolutamente insuficientes, e até mesmo inúteis em certas circunstâncias, É que, como sempre enfatizava Calamandrei ${ }^{24}$, há um componente na atividade jurisdicional que não é alcançado por soluções de racionalização ou de técnica interpretativa. É o componente ditado pelas condições pessoais do juiz, seus sentimentos, sua formação, seu grau de independência, seu caráter e, de certo modo, sua própria vontade. Dirigir a força deste componente na direção de sentenças socialmente eficazes é atividade que dependerá, única e exclusivamente, dos padrões e de compromisso pessoal do juiz para com o direito e a sociedade.

\section{Conclusão}

15. Em suma: as normas do direito têm, por sua própria natureza, uma vocação prospectiva e transformadora da sociedade. Visto sob este enfoque, o direito somente alcançará efetiva realização quando operar transformações no plano da realidade, aproximando-a do ideal normativo. Caberá, portanto, aos operadores do direito e, de modo especial, ao Poder Judiciário - que é seu operador por excelência - interpretá-lo e aplicá-lo pelo modo que proporcione, em grau o mais elevado possível, os resultados sociais previstos idealmente pelo legislador. Com isso e só assim o direito estará consagrado como instrumento legítimo de regulação do Estado e da sociedade.

\section{Notas}

${ }^{1}$ Alexis de Tocqueville, cit. por Henrique P. Haba, in "Tratado basico de Derechos Humanos", Editorial Juricentro, San José-C.R., 1² edição, 1986, vol. II, pág. 881.

2 Pontes de Miranda in Tratado de Direito Privado, Ed. Revista dos Tribunais, $4^{a}$ ediçào, 1974, Tomo I pág. $16 / 17$.

3 Pontes de Miranda in op. cit., pág. 4.

4 José Afonso da Silva in Aplicabilidade das Normas Constitucionais, $2^{22}$ edição, São Paulo, Ed. RT, 1982, págs. 55/56.

5 Léon Duguit in Traité de Droit Constitucionnel, $3^{2}$ edição, Paris, Ancienne Librairie Fontemoing, 1928, pág. 124.

${ }^{6}$ Hans Kelsen in Teoria Geral das Normas, Traduçăo de José Florentino Duarte, Sergio Antonio Fabris Editor, Porto Alegre, 1986, pág. 177/178.

${ }^{7}$ Miguel Reale in Lições Preliminares de Direito, Saraiva, São Paulo, $7^{a}$ edição, 1980, pág. 112/113.

8 Vicente Ráo in O Direito e a Vida dos Direitos,

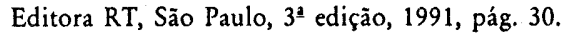

9 Konrad Hesse in Escritos de Derecho Constitucional, Madrid, Centro de Estudios Constitucionales, 1983, pág. 28.

10 Celso Antonio Bandeira de Mello in "Revista de Direito Público", vol, 57/58, 1981, pág. 236 e 238.

11 Anuário Estatístico do Brasil, Rio de janeiro, vol. $52,1992$.

12 Paulo Bonavides in Curso de Direito Constitucional. Malheiros Editores, São Paulo, 1993, $4^{2}$ edição, pág. 307

13 op. cit., pág. 299.

14 Eduardo Novoa Monreal in O Direito Como Obstáculo à Transformação Social, trad. de Gerson Pereira dos Santos, Sérgio Antonio Fabris Editor, Porot Alegre, 1988 , págs. 36

15 Karl Larenz in Metodologia da Ciência do Direito, trad. de José Lamego, Fundação Calouste Gulbenkian, Lisboa, $2^{a}$ edição, pág. 421.

16 German J. Bidart Campos in Teoria General de los Derecbos Humanos, Editora Astrea, Buenos Aires, 1991 págs. 394/399.

17 Jorge Miranda in Manual de Direitos Constitucional , Coimbra Editora, 1968, Tomo II, $2^{2}$ edição, pág. 199/200.
${ }^{18}$ Jorge Miranda in op, cit., pág. 219/220. op. cit., pág. 481.

${ }^{20}$ German J. Bidart Campos in op. cit., págs. 189/191 340

${ }^{21}$ Adolfo Gelsi Bidart in "De Derechos, Deberes y Garan tias, del Hombre Comum" Fundação de Cultura Universitária, Montevidéo, 1987, pág. 119.

${ }^{33}$ German J. Bidart Campos in op. cit., pág. 148. 23 op. cit., pág. 304/305.

24 Piero Calamandrei in Estudios Sobre el Proceso Civil, Ediciones Jurídica Europa-América, Buenos Aires, 1986 vol. III, pág. 235/236

grau o mais elevado possivel, os resultados

